\title{
Right ventricular targeted gene transfer of a $\beta$-adrenergic receptor kinase inhibitor improves ventricular performance after pulmonary artery banding
}

\author{
Sitaram M. Emani, MD \\ Ashish S. Shah, MDa \\ Michael K. Bowman, MDa \\ David C. White, MD ${ }^{\mathrm{a}}$ \\ Sitaramesh Emani, BS ${ }^{a}$ \\ Donald D. Glower, MD \\ Walter J. Koch, $\mathrm{PhD}^{\mathrm{a}, \mathrm{b}}$
}

From the Departments of Surgery, ${ }^{a}$ Pharmacology, and Cancer Biology, ${ }^{\mathrm{b}}$ Duke University Medical Center, Durham, NC.

Supported by National Institute of Health grants HL59533, HL56205, and HL61690 (WJK), as well as a National Service Research Award F32-HL16542 (SME).

Received for publication Feb 11, 2003; revisions requested March 25, 2003; revisions received April 7, 2003; accepted for publication April 29, 2003.

Address for reprints: Walter J. Koch, PhD, Box 2606, MSRB Room 479, Duke University Medical Center, Durham, NC 27710 (E-mail: Koch0002@mc.duke.edu).

J Thorac Cardiovasc Surg 2004;127:787-93 $0022-5223 / \$ 30.00$

Copyright $\odot 2004$ by The American Association for Thoracic Surgery

doi:10.1016/S0022-5223(03)01189-9
Objective: Abrupt increases in right ventricular afterload occur after cardiac transplantation and pulmonary artery banding, which can result in right ventricular hypertrophy and dilatation. Right ventricular dysfunction is also accompanied by $\beta$-adrenergic receptor desensitization. We sought to determine whether selective right ventricular expression of a transgene encoding a $\beta$-adrenergic receptor kinase inhibitor can improve right ventricular remodeling early after pulmonary artery banding.

Methods: Rabbits underwent pulmonary artery banding 3 days after percutaneous right coronary artery injection of empty adenovirus $(n=19)$, a control adenovirus containing the $\beta$-galactosidase transgene $(\mathrm{n}=10)$, or an adenovirus containing the $\beta$-adrenergic receptor kinase inhibitor transgene $(\mathrm{n}=14)$. Sham-operated animals $(n=7)$ underwent instrumentation without deployment of the pulmonary artery band. Right ventricular function was assessed in each rabbit before and 7 days after pulmonary artery banding. Right ventricular mass and dimensions (surface area and volume) were obtained, and biochemical analysis was performed to confirm transgene expression and to characterize $\beta$-adrenergic receptor signaling.

Results: Right ventricular mass was increased in animals treated with adenovirus containing the $\beta$-adrenergic receptor kinase inhibitor transgene, adenovirus containing the $\beta$-galactosidase transgene, and empty adenovirus after banding when compared with results in sham-operated animals. However, right ventricular volume and surface area, as measures of dilatation, were significantly lower in pulmonary artery banded rabbits pretreated with adenovirus containing the $\beta$-adrenergic receptor kinase inhibitor transgene when compared with those treated with empty adenovirus or adenovirus containing the $\beta$-galactosidase transgene. Right ventricular contractility and defective $\beta$-adrenergic receptor signaling were significantly enhanced in rabbits expressing the $\beta$-adrenergic receptor kinase inhibitor after pulmonary artery banding.

Conclusions: Right ventricular preconditioning with the $\beta$-adrenergic receptor kinase inhibitor transgene can attenuate the early right ventricular dilatation and dysfunction associated with pulmonary artery banding. Thus $\beta$-adrenergic receptor kinase inhibition might represent a novel target for limiting ventricular remodeling after increased right ventricular afterload. 


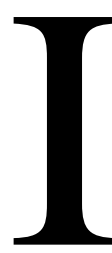

ncreased right ventricular (RV) afterload might occur after cardiac transplantation and certain procedures in congenital heart surgery. ${ }^{1,2}$ Acute RV failure in the postoperative setting could carry up to $70 \%$ mortality despite aggressive management because of the inability of the right ventricle to adequately compensate for the increased afterload. ${ }^{3,4}$ One model of increased RV afterload is pulmonary artery (PA) banding. In this model RV hypertrophy and dilatation occur early and are followed by an eventual impairment in RV contractility. ${ }^{5,6}$ Biochemical abnormalities in hypertrophy and ventricular dysfunction include those of the $\beta$-adrenergic receptor $(\beta A R)$ signaling system. Increased levels of the $\beta$ AR kinase ( $\beta$ ARK1) can lead to enhanced receptor phosphorylation and desensitization. ${ }^{7-10}$

Several studies in genetically engineered mice have provided evidence that increased myocardial $\beta$ ARK1 might be involved in the pathogenesis of ventricular failure, and accordingly, a potential therapeutic strategy for the treatment of heart dysfunction is the inhibition of $\beta$ ARK $1 .{ }^{11}$ The $\beta$ ARKct is a 194-amino-acid peptide corresponding to the carboxyl terminus of $\beta$ ARK1, which competes with $\beta$ ARK1 for receptor binding sites and thus inhibits its activity. Studies in mice and rabbits have shown that cardiac-targeted expression of $\beta$ ARKct leads to enhanced left ventricular (LV) functional performance. ${ }^{12-17}$ However, no study has evaluated the effects of $\beta$ ARKct gene transfer on ventricular function in an animal model of increased ventricular afterload. Furthermore, the effects have not been evaluated in the setting of RV dysfunction. In the present study we examine the effects of intracoronary adenoviralmediated gene transfer of the $\beta$ ARKct to the RV before PA banding on ventricular remodeling and dysfunction.

\section{Methods}

\section{Adenoviral Constructs and Experimental Groups}

The adenovirus backbone for the $\beta$ ARKct transgene (Adeno$\beta A R K c t)$ and the control empty adenovirus (EV) is a secondgeneration adenovirus with deletions of the $\mathrm{E} 1$ and $\mathrm{E} 4 .{ }^{16,18} \mathrm{~A}$ second control virus containing the gene encoding $\beta$-galactosidase $(\beta \mathrm{Gal})$ was constructed by using a first-generation adenovirus. ${ }^{19}$ New Zealand White rabbits $(2.5 \mathrm{~kg})$ were randomly assigned to receive control EV $(\mathrm{n}=19)$, adenovirus containing the $\beta$-galactosidase transgene (Adeno- $\beta \mathrm{Gal} ; \mathrm{n}=10$ ), or Adeno- $\beta$ ARKct ( $\mathrm{n}=$ 14). A separate group of sham-operated animals $(n=7)$ did not undergo either gene transfer or PA band deployment. All animals were treated in accordance with guidelines published by the National Institutes of Health (publication no. 86-23, revised 1985).

\section{PA Band Placement and In Vivo Intracoronary Gene Delivery}

Before gene delivery, rabbits underwent placement of a deployable PA band. After achievement of general anesthesia (inhaled isoflurane), the PA was isolated through a left thoracotomy. A band, consisting of a $2 \times 10-\mathrm{mm}$ strip of reinforced silicone rubber
(Silastic) with 2-0 silk suture tails at both ends, was positioned with the strip loosely encircling, but not compressing, the PA. The tails of the band apparatus were passed through a Silastic tube, externalized from the thoracic cavity, and placed in a subcutaneous pocket to allow access for subsequent band deployment. After recovery (2-4 days), rabbits received selective infusion of adenovirus into the right coronary artery (RCA), which was performed as previously described. ${ }^{19}$ Briefly, after achievement of light sedation $(55 \mathrm{mg} / \mathrm{kg}$ ketamine administered intramuscularly) and local anesthesia (1\% lidocaine), the left carotid artery was isolated. A 3.0F angle-tipped catheter (Cook) was advanced intraluminally into the RCA under fluoroscopic guidance. ${ }^{19}$ Sham-operated animals underwent sedation and catheterization without gene delivery.

\section{PA Band Deployment}

After gene delivery, rabbits were recovered for 4 days to allow for transgene expression and then underwent PA band deployment. During light sedation and local anesthesia, a right cervical incision was made, and a $2.5 \mathrm{~F}$ micromanometer (Millar Instruments) was introduced into the jugular vein and advanced into the right ventricle to measure RV pressures. ${ }^{19} \mathrm{~A}$ separate incision was made on the left chest wall over the subcutaneous pocket containing the tails of the PA band. The band was deployed by advancing the Silastic tube over the suture tails, leading to external compression of the PA. The internal diameter of the band after deployment is $3.2 \mathrm{~mm}$. Successful band deployment was confirmed by observing an increase in RV pressures. Sham-operated animals underwent sedation and catheterization without band deployment. The surgeon performing the band deployment procedure was blinded to the treatment status (ie, Adeno- $\beta$ ARKct, Adeno- $\beta \mathrm{Gal}$, or EV) of each animal. After 30 minutes of monitoring, RV mean ejection pressure and $\mathrm{dP} / \mathrm{dt}_{\max }$ were recorded.

Determination of RV Volume, Mass, and Surface Area After 7 days, repeat RV hemodynamic measurements were obtained by means of jugular vein cutdown and micromanometry. Animals were killed by means of intravenous injection of $20 \mathrm{mEq}$ of $\mathrm{KCl}$, and hearts were harvested. The RV free wall was excised from the heart, and ventricular masses were obtained. RV free wall surface area was measured by means of planimetry. ${ }^{16}$ In a subset of animals ( $\mathrm{n}=5$, Adeno- $\beta$ ARKct; $\mathrm{n}=5$, EV; and $\mathrm{n}=5$, sham), unstressed intraventricular RV volumes were measured before RV dissection by using the following technique. Harvested hearts were placed in $4^{\circ} \mathrm{C}$ cardioplegia solution, and atria were ligated at the atrioventricular groove. Cannulae were inserted retrograde through the PA and aorta into the RV and LV chambers and secured in place with external ties. RV intraventricular volume (at $5 \mathrm{~mm} \mathrm{Hg}$ ) was measured by pressurizing the left ventricle to $10 \mathrm{~mm} \mathrm{Hg}$ and infusing normal saline solution into the right ventricle until the intraventricular pressure reached $5 \mathrm{~mm} \mathrm{Hg}$. The volume of infusate was determined to be the unstressed $\mathrm{RV}$ volume (at $5 \mathrm{~mm} \mathrm{Hg}$ ). Volume measurement was repeated 3 times in each heart, and the mean value of these measurements was documented. Echocardiography (subxyphoid approach, variable 5-12 $\mathrm{MHz}$ probe) with color Doppler flow analysis was used to estimate the peak pressure gradient across the PA band. 


\section{Confirmation of Transgene Expression}

To detect the presence of $\beta$ ARKct mRNA, Northern blot analysis was performed on RV and LV samples from $\beta A R K c t-t r e a t e d$, EV-treated, and sham-operated animals, as described previously. ${ }^{16}$ $\beta \mathrm{Gal}$ staining was performed on ventricular samples from animals treated with the Adeno- $\beta \mathrm{Gal}$ transgene. ${ }^{19}$

\section{Myocardial $\beta A R$ Density and Signaling}

Membranes were prepared, and total $\beta$ AR density was determined by means of radioligand binding with a saturating concentration (300 pmol/L) of iodine 125 -labeled cyanopindolol at $37^{\circ} \mathrm{C}$ for 1 hour. ${ }^{16,17}$ To measure membrane adenylyl cyclase activity, $20 \mu \mathrm{g}$ of myocardial membrane protein was incubated with $0.1 \mu \mathrm{mol} / \mathrm{L}$ $\left[\alpha^{-}{ }^{32}\right]$ adenosine triphosphate for 15 minutes at $37^{\circ} \mathrm{C}$ under basal conditions or in the presence of $1 \mathrm{mmol} / \mathrm{L}$ isoproterenol or 10 $\mathrm{mmol} / \mathrm{L}$ sodium fluoride, and cyclic adenosine monophosphate (cAMP) production was quantified by using standard methods. ${ }^{16,17}$ Myocardial $\beta$ ARK1 levels were detected by means of immunoblotting for $\beta$ ARK1, as previously described. ${ }^{9,20}$

\section{Statistical Analysis}

Actual survival after 7 days of PA banding in each group was compared, and a $\chi^{2}$ test was performed to determine statistical significance. Hemodynamic and geometric parameters were compared by means of analysis of variance and are expressed as means \pm SE. The post hoc Sheffe subgroup test was performed to compare individual groups if statistical significance was achieved by using analysis of variance. A Student $t$ test was used to compare adenylyl cyclase activities between groups.

\section{Results}

\section{RV-Targeted Transgene Delivery}

Northern blot analysis was performed to detect $\beta$ ARKct transgene expression in ventricular samples from treated rabbits. $\beta A R K c t$ mRNA expression is RV specific and is seen only in the Adeno- $\beta$ ARKct-treated animals (Figure 1, $A)$. The distribution of $\beta \mathrm{Gal}$ expression in the $\mathrm{RV}$ and septum (Figure 1,B) is consistent with previous data on subselective coronary artery catheterization and adenovirus injection into the rabbit heart. ${ }^{19}$

\section{PA Banding, Hypertrophy, and Survival}

All rabbits used had similar body weights (Table 1). The mean peak pressure gradient across the PA band, as measured by means of Doppler imaging, did not differ significantly between animals pretreated with Adeno- $\beta$ ARKct or EV ( $23 \pm 7$ vs $20 \pm 5 \mathrm{~mm} \mathrm{Hg}, P=$ not significant) after 7 days of banding. Rabbits pretreated with control viruses or Adeno- $\beta$ ARKct had higher RV masses after PA banding when compared with sham-operated control animals, but LV mass was similar among groups (Table 1). We found a significant difference in 7-day survival when rabbits pretreated with control adenovirus were compared with those treated with Adeno- $\beta$ ARKct (14/29 [48\%] vs 13/14 [93\%], respectively; $P=.01, \chi^{2}$ test; Table 1$)$. At the time of necropsy, surgical complications, such as arterial rupture, band migration, and infection, were excluded as causes of death. Animals that died appeared to have RV dilatation, mild bilateral pleural effusions, and, occasionally, ascites.

\section{Physiologic Effects of $\beta$ ARKet Expression on PA Banding}

Mean hemodynamic parameters measured at the time of PA banding are presented in Table 1. Measurements were taken before and immediately after band deployment. There were no significant differences in heart rate between the control (EV and $\beta \mathrm{Gal}$ ) and Adeno- $\beta \mathrm{ARKct}-$ treated groups at either time point (Table 1). RV peak systolic blood pressure and end-diastolic pressure increased appropriately after PA banding, but there were no differences between groups (Table 1). RV dP/dt ${ }_{\max }$, as a measure of ventricular contractility, was similar in all groups before band deployment but was significantly higher after PA banding in rabbits pretreated with Adeno- $\beta$ ARKct compared with values in rabbits treated with control viruses or sham-operated rabbits $(P<.05)$.

Unstressed RV volume was significantly lower in Adeno- $\beta$ ARKct-treated rabbits compared with in EV-treated animals but was lowest in sham-operated animals (Table 1). We also assessed RV dilatation by measuring unstressed ventricular free wall surface area by means of planimetry. PA-banded rabbits pretreated with Adeno- $\beta$ ARKct had a significantly lower mean surface area compared with those pretreated with EV. Both of these values were higher than the mean surface area measured in sham-operated control animals (Table 1).

\section{BAR Signaling Effects of PA Banding and BARKct Expression}

To assess biochemical changes induced in the RV after PA banding, we assessed $\beta$ AR density, $\beta$ ARK1 levels, and adenylyl cyclase activity. Mean RV $\beta$ AR density was not different between each group of animals (data not shown). $\beta$ ARK1 levels were increased in ventricular samples from PA-banded rabbits, and levels were higher in the right ventricle compared with in the left ventricle of all banded animals (Figure 2). Pretreatment with Adeno- $\beta$ ARKct before PA band deployment did not alter increased $\beta$ ARK1 levels after PA banding.

To investigate whether increased $\beta$ ARK1 affected $\beta$ AR signaling, we measured adenylyl cyclase activity in membranes prepared from the various right ventricles. As shown in Figure 3, PA banding did result in decreased basal, isoproterenol-mediated, and sodium fluoride-mediated cAMP production. However, these were normalized in the Adeno- $\beta$ ARKct-treated rabbits. In terms of $\beta$ AR responsiveness (isoproterenol stimulation over basal cAMP), banded values $(20 \% \pm 4 \%, \mathrm{n}=4)$ were significantly 

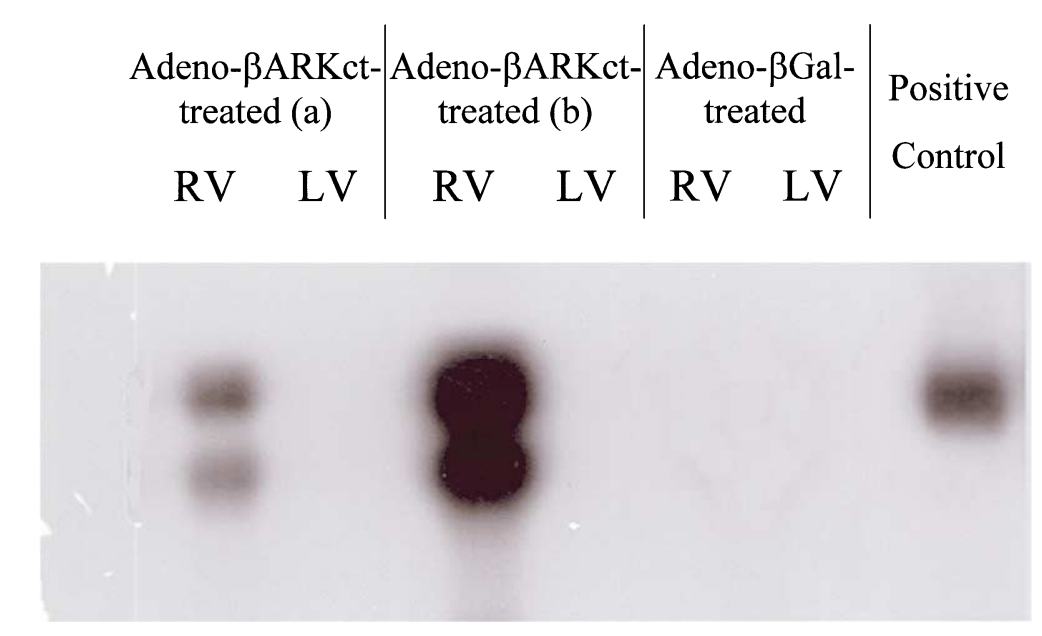

A

B

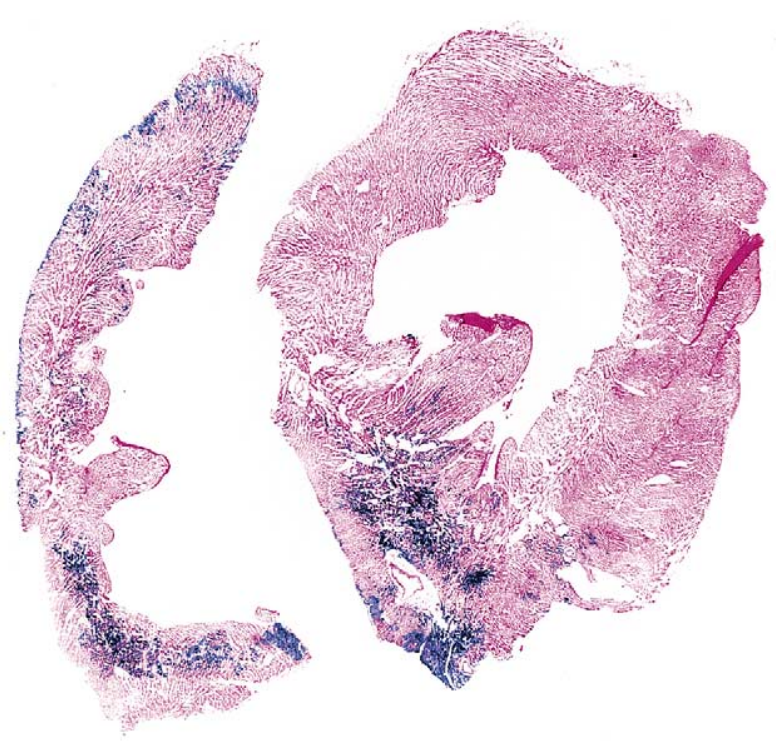

Figure 1. A, $\beta$ ARKct transgene expression after RCA adenovirus delivery. RV-specific $\beta$ ARKct mRNA expression was confirmed by means of Northern blot analysis of total RNA isolated from the RV and LV of 2 separate ( $a$ and b) Adeno- $\beta$ ARKct-treated rabbits while absent from an Adeno- $\beta$ Gal-treated animal. B, Representative Xgal staining of a cross-section obtained from a banded animal pretreated with Adeno- $\beta$ Gal. (Original magnification $4 \times$.)

decreased compared with sham values $(43 \% \pm 11 \%, \mathrm{n}=4$, $P<.05)$, whereas $\beta$ ARKct restored this response (53\% \pm $10 \%, \mathrm{n}=4, P<.05$ vs banded).

\section{Discussion}

The present study demonstrates that RV-specific, adenoviral-mediated gene transfer of the $\beta$ ARKct peptide in a model of acute ventricular pressure overload can significantly alter the course of early RV dysfunction. We targeted $\beta$ ARK1 activity because this kinase appears to be involved in the pathogenesis of ventricular dysfunc- tion and heart failure. ${ }^{11}$ Selective RV expression of the $\beta$ ARKct, which inhibits $\beta$ ARK1 through competition for $\mathrm{G}_{\beta \gamma}$ binding and membrane translocation, ${ }^{12}$ was accomplished by means of percutaneous, catheter-mediated RCA injection of Adeno- $\beta$ ARKct. Importantly, we found that RV-specific $\beta$ ARKct expression before PA banding limits RV dilatation and improves contractility and survival early in the course of ventricular remodeling. The physiologic changes were associated with near normalization of intracellular $\beta$ AR signaling, suggesting functionality of the $\beta$ ARKct transgene. 
PA banding in rabbits is a model of severe right-heart failure leading to early RV dysfunction and mortality. Seven days after PA banding, the increased afterload placed on the right ventricle resulted in a near doubling of the RV mass and volume. The surface area of the right ventricle was also significantly increased 7 days after PA banding. Moreover, PA banding was accompanied by a high mortality in rabbits that received the control EV. This model was used for several reasons. First, the time course and severity of RV dysfunction is reproducible and resembles the early RV failure seen in clinical settings of acute pressure overload. Second, the degree of banding achieved was similar in each animal because the band diameter was constant and animal size was similar between groups, thus decreasing variability in PA size.

The beneficial effects of $\beta$ ARKct on RV dysfunction after PA banding is consistent with previous studies that have demonstrated the benefits of $\beta$ ARK1 inhibition in other models of heart failure. Transgenic mice with cardiac $\beta$ ARKct expression have enhanced cardiac function ${ }^{12}$ that is preserved in LV pressure overload hypertrophy, ${ }^{9}$ and concurrent $\beta$ ARKct expression has shown benefit in several murine models of heart failure. ${ }^{13-15}$ In addition to these mouse studies, Adeno- $\beta$ ARKct has also led to positive effects in a rabbit model of $\mathrm{LV}$ dysfunction after myocardial infarction. ${ }^{16,17}$ The present study differs from previous studies in several important ways. First, in addition to showing improvement in contractility, we demonstrate a favorable effect of $\beta$ ARK inhibition on early ventricular dilatation, which has not been previously described. Second, whereas previous studies have focused on treatment of LV dysfunction, the potential benefit of $\beta$ ARKct has now been shown specifically for RV dysfunction in the setting of acute pressure overload. Finally, the therapeutic strategy used in this study was pretreatment of the right ventricle by means of gene transfer several days before imposition of the increased afterload, thus allowing an adequate interval for $\beta$ ARKct expression. This strategy of genetic preconditioning through RCA-mediated $\beta$ ARKct injection might be useful in appropriate clinical settings, such as before planned surgical procedures in which increased RV afterload is anticipated.

The fact that hypertrophy was not prevented by $\beta$ ARKct expression is not surprising because a previous study in mice has shown that the hypertrophic response in the left ventricle after aortic constriction was not altered by myocardial-targeted $\beta$ ARKct expression. ${ }^{9}$ However, the $\beta A R K c t$ did restore ventricular dysfunction associated with pressure-overload hypertrophy, ${ }^{9}$ which is consistent with our findings in the present study showing improvement in $\mathrm{RV}$ contractility in Adeno- $\beta$ ARKct-treated rabbits after PA banding. We have previously shown that $\beta$ ARK1 is upregulated in certain forms of hypertrophy, including LV pressure
TABLE 1. Hemodynamics, survival, and ventricular dimensions

\begin{tabular}{|c|c|c|c|}
\hline & $\begin{array}{c}\text { BARKct } \\
(n=14)\end{array}$ & $\begin{array}{l}\mathrm{EV} / \boldsymbol{\beta G} \mathrm{Gal} \\
(\mathrm{n}=29)\end{array}$ & $\begin{array}{l}\text { Sham } \\
(n=7)\end{array}$ \\
\hline BW (kg) & $2.6 \pm 0.3$ & $2.5 \pm 0.2$ & $2.6 \pm 0.2$ \\
\hline \multicolumn{4}{|l|}{ HR (beats/min) } \\
\hline Before banding & $189 \pm 19$ & $194 \pm 31$ & $177 \pm 23$ \\
\hline After banding & $194 \pm 28$ & $203 \pm 38$ & $188 \pm 32$ \\
\hline \multicolumn{4}{|l|}{$\mathrm{SBP}(\mathrm{mm} \mathrm{Hg})$} \\
\hline Before banding & $17.6 \pm 2.4$ & $18.4 \pm 3.2$ & $16.3 \pm 1.7$ \\
\hline After banding & $34.7 \pm 7.1^{*} \ddagger$ & $32.1 \pm 5.9^{*} \ddagger$ & $15.7 \pm 2.2$ \\
\hline \multicolumn{4}{|l|}{$\operatorname{EDP}(\mathrm{mm} \mathrm{Hg})$} \\
\hline Before banding & $2.2 \pm 0.41$ & $1.9 \pm 0.52$ & $2.1 \pm 0.36$ \\
\hline After banding & $3.3 \pm 0.63 \ddagger$ & $3.4 \pm 0.62^{*} \ddagger$ & $2.3 \pm 0.31$ \\
\hline \multicolumn{4}{|l|}{$\mathrm{dP} / \mathrm{dt}_{\max }(\mathrm{mm} \mathrm{Hg} / \mathrm{s})$} \\
\hline Before banding & $447 \pm 31$ & $439 \pm 34$ & $431 \pm 29$ \\
\hline After banding & $653 \pm 51^{*} \dagger \ddagger$ & $539 \pm 45^{*} \ddagger$ & $425 \pm 30$ \\
\hline 7-d survival & $92.8 \% \dagger$ & $48.3 \%$ & $100 \%$ \\
\hline LV mass $(\mathrm{g}) \S$ & $3.56 \pm 0.23$ & $3.62 \pm 0.31$ & $3.52 \pm 0.18$ \\
\hline RV mass $(\mathrm{g}) \S$ & $1.8 \pm 0.13 \ddagger$ & $1.8 \pm 0.10 \ddagger$ & $0.94 \pm 0.09$ \\
\hline RV surface area $\left(\mathrm{cm}^{2}\right) \S$ & $5.9 \pm 0.28 \dagger \ddagger$ & $7.1 \pm 0.33 \ddagger$ & $4.9 \pm 0.12$ \\
\hline RV volume $\left(\mathrm{cm}^{3}\right) \|$ & $1.9 \pm 0.30 \dagger \ddagger$ & $2.9 \pm 0.40 \ddagger$ & $1.3 \pm 0.20$ \\
\hline
\end{tabular}

$B W$, Body weight; $H R$, heart rate; $S B P$, systolic blood pressure; $E D P$, end-diastolic pressure.

${ }^{*} P<.05$, after banding versus before banding.

$\dagger P<.05$, versus $\mathrm{EV} / \beta \mathrm{Gal}$.

$\ddagger P<.05$, versus sham.

$\S \beta$ ARKct, $\mathrm{n}=13 ; \mathrm{EV}, \mathrm{n}=10$; sham, $\mathrm{n}=7$.

$\| \beta A R K c t, n=5 ; E V / \beta G a l, n=5$; sham, $n=5$.

overload and RV volume overload, and that increased desensitization is responsible for $\beta A R$ uncoupling and not $\beta$ AR downregulation. ${ }^{9,10,20}$ Similarly, in this study we found that RV pressure overload in the rabbit is associated with $\beta$ ARK1 upregulation, which is not reversed by $\beta$ ARKct expression. Importantly, although expression of the $\beta$ ARKct does not alter the increased $\beta$ ARK1 expression, it apparently can block any enhanced activity of this upregulated kinase, as evidenced by normalization of adenylyl cyclase activity in banded animals treated with Adeno- $\beta$ ARKct.

The distribution of transgene expression is consistent with previous experience using subselective RCA injection. $\beta \mathrm{Gal}$ expression was seen in the RV free wall and interventricular septum, and $\beta$ ARKct mRNA was demonstrated only in RV samples. $\beta A R K c t$ transgene expression was inferred from the presence of mRNA and evidence of downstream biochemical activity (restoration of adenylyl cyclase activity).

Ventricular contractility was assessed by using micromanometry to derive $\mathrm{dP} / \mathrm{dt}_{\max }$ and global hemodynamics. DP/dt is a crude measure of contractility because it is both preload and afterload dependent. Although preload-independent measures of RV function are more sensitive than $\mathrm{dP} / \mathrm{dt}$, techniques used to obtain these measurements (conductance catheter, magnetic resonance imaging, and ultra- 


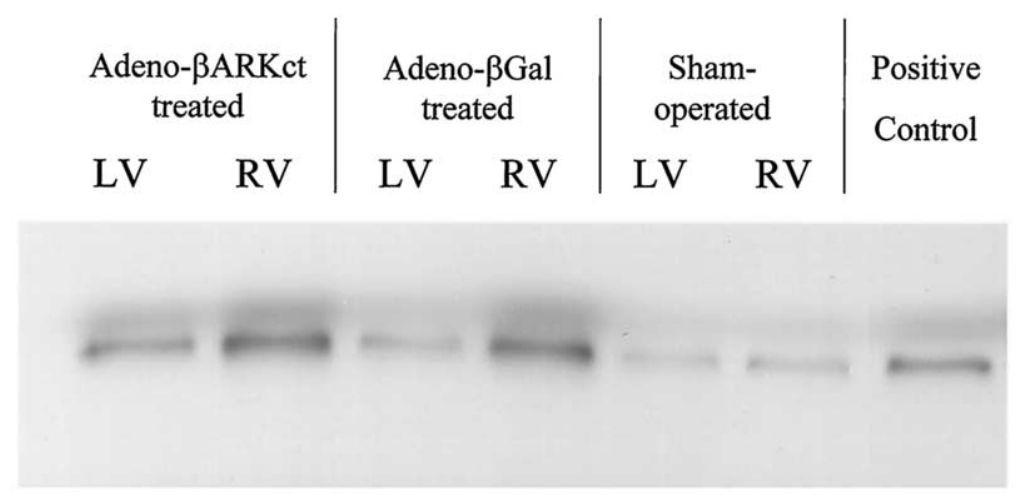

Figure 2. $\beta$ ARK1 protein levels in ventricular samples. $\beta$ ARK1 content was visualized by means of Western blotting after immunoprecipitation with a monoclonal antibody, as described previously. ${ }^{9,20}$ Shown is a representative blot for ventricular (RV and LV) $\beta A R K 1$ levels in listed animals.

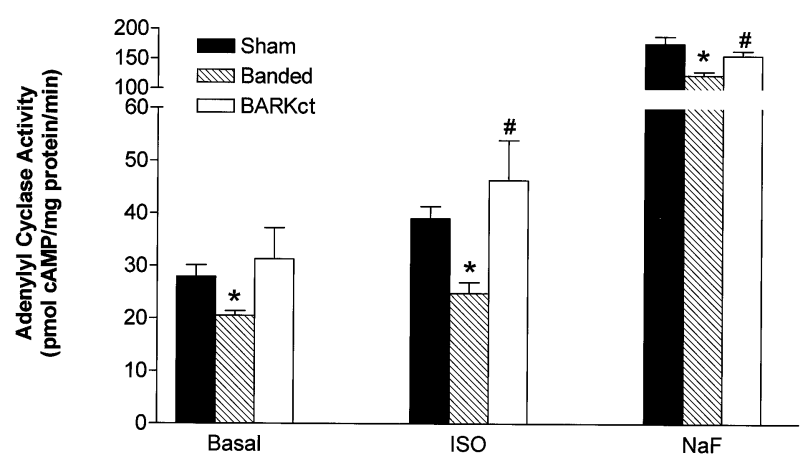

Figure 3. RV membrane adenylyl cyclase activity. Basal, isoproterenol (ISO)-stimulated, and NaF-stimulated activities were all reduced after PA banding (EV treated) compared with sham values and normalized with Adeno- $\beta$ ARKct treatment. Data shown are the means \pm SEM of 4 experiments, each done in triplicate. ${ }^{*} P<.05$ versus sham; \#P $<.05$ versus banded.

sonic transducers) are unreliable when applied to the right ventricles of small animals. Despite the relative lack of sensitivity of $\mathrm{dP} / \mathrm{dt}$, we were able to detect a significant difference between the control and treated groups.

Although ventricular dilatation was attenuated in $\beta$ ARKct-expressing animals, unstressed RV volume and free wall surface area did not completely normalize when compared with that of sham-operated animals. The exact mechanisms contributing to ventricular dilatation are poorly understood but are thought to include myocyte slippage, elongation of the cardiac cell, extracellular matrix remodeling, myocyte dropout, and altered intracellular signaling pathways. ${ }^{21,22}$ A plausible mechanism by which $\beta$ ARKct prevents ventricular dilatation is by altering $G$ proteincoupled receptor signaling pathways (including $\beta$ ARs) either due directly to $\beta$ ARK1 inhibition or possibly additional pathways involving $\mathrm{G}_{\beta \gamma}$-mediated signaling, which is an alternative mechanism of $\beta$ ARKct action. ${ }^{11}$ Importantly, some extracellular contributions to ventricular dilatation (myocyte slippage and extracellular matrix remodeling) are less likely to be affected by $\beta$ ARKct, which is consistent with our finding that RV dilatation was not completely inhibited by Adeno- $\beta$ ARKct treatment.

One limitation of the study arises from the difference in mortality between the control and treatment groups. Necropsy was performed on all early fatalities, and evidence of massive ventricular dilatation and right heart failure (ascites and peripheral edema) was seen almost universally. Because the values of RV dimensions and hemodynamics in the control group might be underestimated, the differences between the Adeno- $\beta$ ARKct and control groups might also be underestimated.

Another limitation of the current study is the acute window of observation. Accordingly, the long-term effects of $\beta$ ARKct expression on ventricular performance in the setting of chronically increased RV afterload were not apparent. Nevertheless, we did find significant attenuation of RV remodeling and dysfunction 7 days after PA banding, demonstrating the benefits of genetic preconditioning on the early phase of acute pressure overload. In clinical situations such as cardiac transplantation, RV dysfunction is a major cause of acute graft failure in the immediate postoperative period. ${ }^{1,2}$ Such dysfunction is often refractory to administration of systemic inotropic agents. ${ }^{3,4}$ Patients with postoperative refractory acute RV failure rarely require extended mechanical support, with the duration of support ranging from 2 hours to 8 days. ${ }^{3}$ Thus pretreatment of the right ventricle with $\beta$ ARKct, even if expression is transient, might be adequate for temporary RV support immediately after imposition of increased afterload.

We thank K. Wilson and S. Duncan for excellent technical assistance and the Genzyme Corporation (Framingham, Mass) for 
preparation and purification of EV and Adeno- $\beta$ ARKct. We also thank Dr Robert J. Lefkowitz for support and discussions.

\section{References}

1. Hosenpud JD, Bennet LE, Keck BM, et al. The Registry of the International Society for Heart and Lung Transplantation: fifteenth official report 1998. J Heart Lung Transplant. 1998;17:656-68.

2. Warnecke I, Bein G, Bucherl ES. The relevance of intraoperative pressure and oxygen saturation monitoring during pulmonary artery banding in infancy. J Cardiothorac Anesth. 1989;3:31-6.

3. Kaul TK, Fields BL. Postoperative acute refractory right ventricular failure: incidence, pathogenesis, management and prognosis. Cardiovasc Surg. 2000;8:1-9.

4. Chen JM, Levin HR, Rose EA, et al. Experience with right ventricular assist devices for perioperative right sided circulatory failure. Ann Thorac Surg. 1996;61:305-10.

5. Hsieh CM, Mishkel GJ, Cardoso PF, et al. Production and reversibility of right ventricular hypertrophy and right heart failure in dogs. Ann Thorac Surg. 1992;54:104-10.

6. Welham KC, Silove ED, Wyse RK. Experimental right ventricular hypertrophy and failure in swine. Cardiovasc Res. 1978;12:61-5.

7. Bohm M, Flesch M, Schnabel P. Beta-adrenergic signal transduction in the failing and hypertrophied myocardium. J Mol Med. 1997;75: 842-8.

8. Anderson KM, Eckhart AD, Willette RN, Koch WJ. The myocardial $\beta$-adrenergic system in spontaneously hypertensive heart failure (SHHF) rats. Hypertension. 1999;33:402-7.

9. Choi DJ, Koch WJ, Hunter JJ, Rockman HA. Mechanism of $\beta$-adrenergic receptor desensitization in cardiac hypertrophy is increased $\beta$-adrenergic receptor kinase. J Biol Chem. 1997;272:17223-9.

10. Shah AS, Atkins BZ, Hata JA, et al. Early effects of right ventricular volume overload on ventricular performance and $\beta$-adrenergic signaling. J Thorac Cardiovasc Surg. 2000;120:342-9.

11. Rockman HA, Koch WJ, Lefkowitz RJ. Seven membrane spanning receptors and heart function. Nature. 2002;415:206-12.

12. Koch WJ, Rockman HA, Samama P, et al. Cardiac function in mice overexpressing the $\beta$-adrenergic receptor kinase or a $\beta$ ARK inhibitor. Science. 1995;268:1350-3.

13. Rockman HA, Chien KR, Choi D-J, et al. Expression of a $\beta$-adrenergic receptor kinase 1 inhibitor prevents the development of heart failure in gene targeted mice. Proc Natl Acad Sci U S A. 1998;95:7000-5.

14. Harding V, Jones L, Lefkowitz RJ, et al. Cardiac $\beta$ ARK1 inhibition prolongs survival and augments $\beta$ blocker therapy in a mouse model of severe heart failure. Proc Natl Acad Sci U S A. 2001;98:5809-14.

15. Freeman K, Olsson MC, Iaccarino G, et al. Manipulation of cardiac adrenergic signaling and calcium cycling have markedly different effects on the progression of cardiomyopathy. J Clin Invest. 2001;107: 967-74.

16. White DC, Hata JA, Shah AS, et al. Preservation of myocardial $\beta$-adrenergic receptor signaling delays the development of heart failure after myocardial infarction. Proc Natl Acad Sci U S A. 2000;97:542833.

17. Shah AS, White DC, Emani S, et al. In vivo ventricular gene delivery of a $\beta$-adrenergic receptor kinase inhibitor to the failing heart reverses cardiac dysfunction. Circulation. 2001;103:1311-6.

18. Hehir KM, Armentano D, Cardoza LM, et al. Molecular characterization of replication-competent variant of adenovirus vectors and genome modifications to prevent their occurrence. J Virol. 1996;70: 8459-67.

19. Shah AS, Lilly RE, Kypson AP, et al. Intracoronary adenovirusmediated delivery and overexpression of the $\beta 2$-adrenergic receptor in the heart: prospects for molecular ventricular assistance. Circulation. 2000;101:408-14.

20. Iaccarino G, Tomhave ED, Lefkowitz RJ, Koch WJ. Reciprocal in vivo regulation of myocardial $\mathrm{G}$ protein-coupled receptor kinase expression by $\beta$-adrenergic receptor stimulation and blockade. Circulation. 1998;98:1783-9.

21. Francis GS. Changing the remodeling process in heart failure: basic mechanisms and laboratory results. Curr Opin Cardiol. 1998;13:15661 .

22. Woodiwiss AJ, Tsotetsi OJ, Sprott $\mathrm{S}$, et al. Reduction in myocardial collagen cross-linking parallels left ventricular dilatation in rat models of systolic chamber dysfunction. Circulation. 2001;103:155-60. 